Life Science Informatics Publications

Research Journal of Life Sciences, Bioinformatics, Pharmaceutical and Chemical Sciences

Original Review Article

DOI: $10.26479 / 2019.0503 .19$

REVIEW: BIOCHEMICAL STUDIES ON CHLOROGENIC ACID \& ITS PHARMACOLOGICAL EFFECT

\title{
Raya Roy*
}

Department of Biotechnology, Himachal Pradesh University, Shimla, Himachal Pradesh, India.

\begin{abstract}
Coffee is one of the widely consumed beverages throughout the world and it has some beneficial therapeutic effect. Chlorogenic acids (CGAs) are the most vital ingredient of coffee beans which has been extensively used in nutraceuticals, pharmaceuticals \& medicine. Chlorogenic acid (CGA) is formed from esterification of caffeic acid and (-)quinic acid. CGAs are naturally found as an intermediate in lignin biosynthesis and thus are prevalent in plant kingdom. Emergence of drug resistant microorganism, innumerable side effects of drugs of cancer, blood sugar, obesity etc have triggered the idea to use naturally occurring substances with little or no side effects at all. Most of these may be used as food supplements also in order to get desired results. CGAs are one such phenolic compound found abundantly in plant which has numerous beneficial pharmacological activities. These activities include anti-microbial, anticancer, antioxidant, anti-inflammatory, anti-diabetic, antilipidemic antihypertensive and neuroprotective.
\end{abstract}

KEYWORDS: Chlorogenic acids (CGAs), anticancer, anti-diabetic, anti-inflammatory, antilipedemic, antihypertensive and neuroprotective.

\section{Corresponding Author: Raya Roy*}

Department of Biotechnology, Himachal Pradesh University, Shimla, Himachal Pradesh, India.

\section{INTRODUCTION}

Obesity is one of the most serious health issues of 21st century. In 2015, 600 million adults (12\%) and 100 million children were obese. Obesity is a medical condition in which excess body fat has accumulated to the extent that it may have a negative effect on health. Obesity is stigmatized in much of the modern world (particularly in the Western world). Changes in the diet and exercising are the mainstream treatments of obesity. However, in modern lifestyle there is very little time for exercising. So dietary supplements must be given to reduce body fats. Side effects with weight loss drugs can 
vary depending upon the type of drug you take and how the drug works. Stimulants-type drugs like phentermine can lead to insomnia, increased blood pressure, fast heart rate, restlessness, drug dependence and abuse, and withdrawal symptoms. Drugs that interfere with fat absorption, such as orlistat (Alli), can lead to oily spotting, gas, and soft stools. Diet pills that affect neurotransmitters in the brain, such as Belviq (lorcaserin) or Contrave (bupropion and naltrexone) can be linked with headache, nausea and vomiting, constipation, dry mouth, and dizziness. Thus, researchers have focussed on advancement of anti obesity drugs from plant sources with little toxicity. Drugs extracted from plants sources is of great importance and many plant-derived compounds like polyphenols, flavanoids and terpenoids are of enormous nutritional and medicinal value and comprehensively studied for their potential as beneficial effects on human health. When plant foods are consumed, the bioavailability of plant derived compounds may elicit a variety of important bioactivities. Recently like green tea, extract made from green coffee beans have received much interest from researchers with increasing investigation as a possible health-promoting supplement. Green coffee beans are rich source of chlorogenic acids. Chlorogenic acids (CGAs)are by products of cinnamic acid. Caffeoylquinic acids (CQA)and dicaffeoylquinic acids (diCQA) are the main CGA found in green coffee beans and it is recorded to have strong antibacterial and anti- inflammatory effects. However, the cytotoxicity effect of 5CQA on adipocyte cell lines has not been confirmed. In the present study we have made an attempt to screen antilipogenic activity of 5CQA, a decaffeinated green coffee bean extract. Even though pharmacological industries have produced a number of new antibiotics in the last three decades, resistance to these drugs by microorganisms has increased. In general, bacteria have the genetic ability to transmit and acquire resistance to drugs, which are utilized as therapeutic agents. After the revolution in the "golden era", when almost all groups of important antibiotics (tetracyclines, cephalosporins, aminoglycosides and macrolides) were discovered and the main problems of chemotherapy were solved in the 1960s, the history repeats itself nowadays and these exciting compounds are in danger of losing their efficacy because of the increase in microbial resistance. Currently, its impact is considerable with treatment failures associated with multidrug- resistant bacteria and it has become a global concern to public health. The problem of microbial resistance is growing and the outlook for the use of antimicrobial drugs in the future isstill uncertain. Therefore, actions must be taken to reduce this problem, for example, to control the use of antibiotic, develop research to better understand the genetic mechanisms of resistance, and to continue studies to develop new drugs, either synthetic or natural. The ultimate goal is to offer appropriate and efficient antimicrobial drugs to the patient. For a long period of time, plants have been a valuable source of natural products for maintaining human health, especially in the last decade, with more intensive studies for natural therapies. The use of plant extracts and phytochemicals, both with known antimicrobial properties, can be of great significance in therapeutic treatments. 


\section{Chlorogenic acid}

CGA also called Cyclohexanecarboxylic acid, 3-[[3-(3,4- dihydroxyphenyl)-1-oxo-2propenyl]oxy]-1,4,5-trihydroxy-, [1S-(1,3ß,4,5)-(9CI), is a biologically active polyphenol formed by an ester bond between caffeic acid and quinic acid[1]. Chlorogenic acid is formed as the byproduct of cinnamic acid and functions as an intermediate in lignin biosynthesis [2]. The term "chlorogenic acids" typically includes at least five groups of isomers including caffeoylquinic acids, dicaffeoylquinic acids, and feruloylquinic acids.Upon oxidation chlorogenic acid dispense green colour hence the name. Isomers of chlorogenic acids are formed by the esterification of the caffeoyl group at different hydroxyl group on the quinic acid ring [3].

Seven such Caffeoylquinolic acid has been reported which are formed by the addition of one or more than one Caffeoyl groups at distinct position of the quince acid ring. These isomers are namely : 1-O-caffeoylquinic acid, 4-O-caffeoylquinic acid, 5-O-caffeoylquinic acid, 1,5-O-dicaffeoylquinic acid, 1,3-O-di-caffeoylquinic acid, 4,5-O-di-caffeoylquinic acid and 1,3,5-Otricaffeoylquinic acid [4].

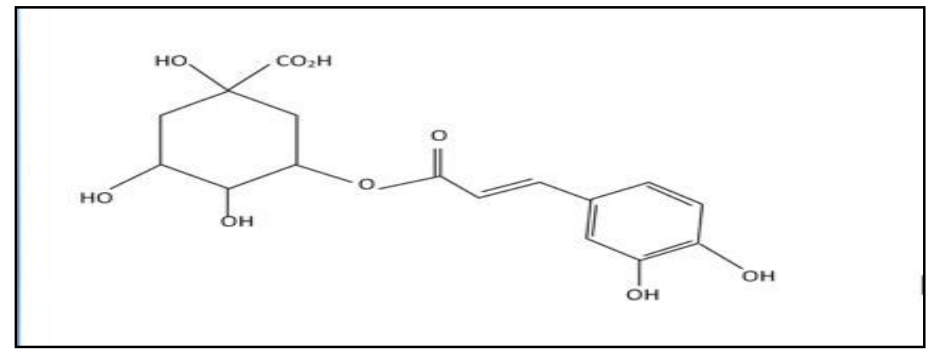

\section{Figure 1: Caffeoylquinolic acid (Chlorogenic acid)}

\section{Natural occurrence of Chlorogenic acid}

Chlorogenic acid is widely distributed in the plant kingdom as an antioxidant. Green coffee and green tea contains a tremendous amount of chlorogenic acid. Others include dicotyledonous plants (Caprifoliaceae, Compositae, Cruciferae, Cucurbitaceae, Labiatae, Leguminosae, Polygonaceae, Saxifragaceae, Solanaceae, Theaceae, Umbelliferae, and Valerianaceae), vegetables (Chinese, red, savoy, and white cabbages, carrots, cauliflower, celery, kale, kohlrabi, eggplant, lettuce, onions, peas, sweet peppers, potatoes etc), fruits (blueberries; black, red, and white currants; green, yellow, and red gooseberries, grapefruits, lemons, oranges; strawberries, sweet melons; and watermelons) and medicinal plants (B. folium, O. folium, and S. herba) [5-7].

\section{Biosynthesis of Chlorogenic acid}

Coffee plants especially coffea Arabica synthesise various isomers of chlorogenic acid namely CQA, diCQA, FQA. The most abundant of them is the 5CQA. Structurally, chlorogenic acid is the ester formed between caffeic acid and the 3-hydroxyl of L-quinic acid [8]. The caffeoyl part of 5CQA is formed viathephenylpropanoid pathway derived from phenylalanine (Hahlbrockand Scheel, 1989). The biosynthetic precursor of chlorogenic acid are derivatives of hydroxycinnamoyl-CoA (derived from cinnamic acid) namely, 4-coumaroyl-CoA. Caffeoyl-

(C) 2019 Life Science Informatics Publication All rights reserved 
CoAor 4-coumaroyl-CoA is combined with quinicacid,which is derived by the shikimic acid pathway(Gamborg, 1967). The hydroxylation of the coumaryl ester, i.e. installing thesecond hydroxyl group, is catalyzed by acytochrome P450 enzyme [9]. The pathway which operates in coffee plants suggested the formation of 5CQA via phenylalanine $\rightarrow 5$ cinnamic acid $\rightarrow 4$-coumaric acid $\rightarrow 5$ caffeic acid $\rightarrow 5$ caffeoyl-CoA $\rightarrow$ 5CQA.One of the first enzymes involved in the conversion of phenylalanine to 5-cinnamic acid is PAL (Phenylalanine ammonia lyase). 4coumaroylester 3-hydroxylase then catalyzes the conversion of 4-coumaric acid/4-coumaroylester to caffeic acid/ caffeoylester. Other participating enzymes in CQA and FQA biosynthesis include hydroxycinnamoyl-CoA shikimate/quinate hydroxyl cinnamoyl transferases. These enzymes have broad substrate specificity, including p-coumaroyl-CoA, caffeoyl-CoA, and feruloyl-CoA. 5-CQA appears to be formed from caffeoyl-CoA via feruloyl-CoA. Biosynthesis of chlorogenic acids seems to be controlled by the activity of the phenylpropanoid pathway and the shikimic acid pathway $[10,11]$.

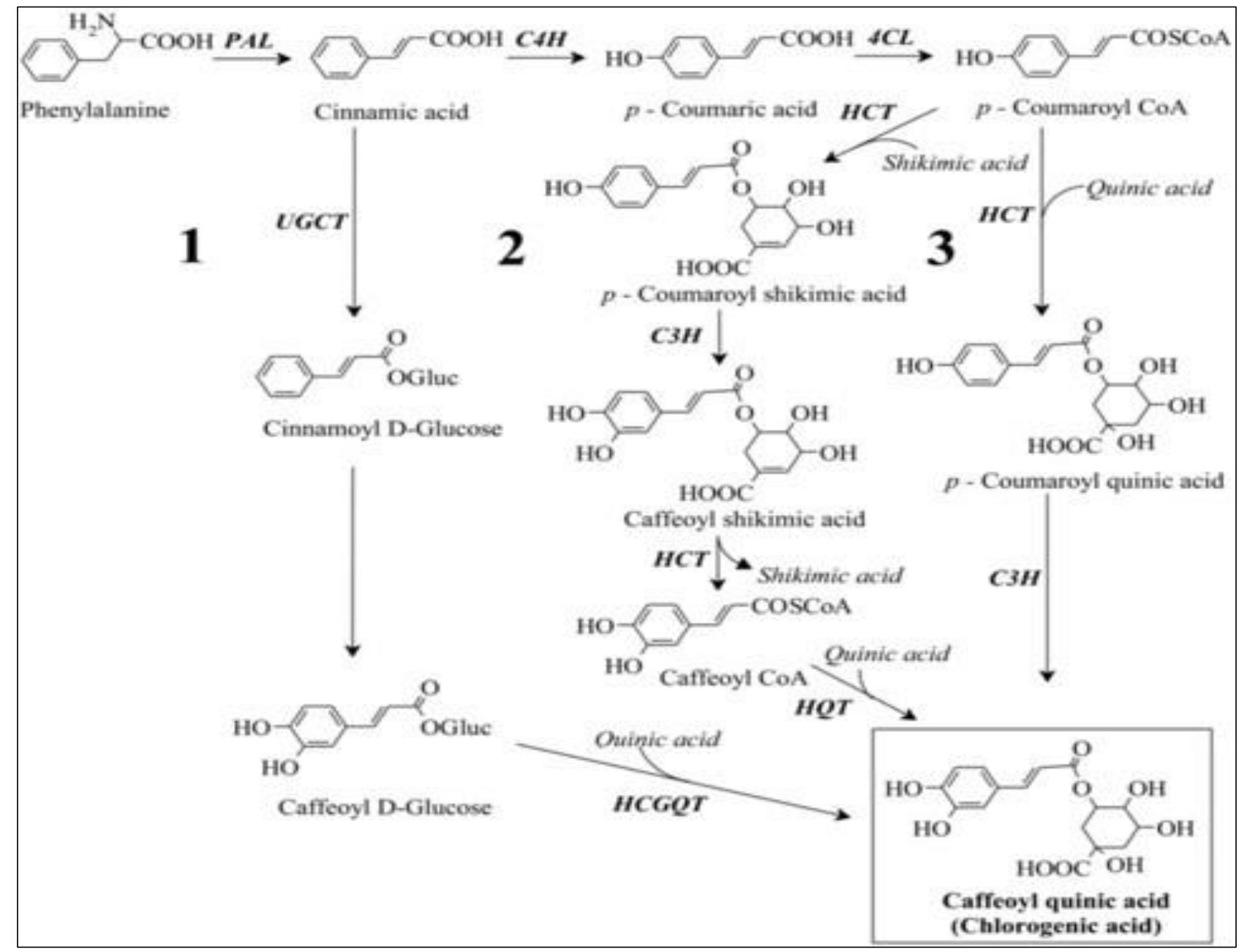

Figure 2: Biosynthesis ofChlorogenic acid [32]

\section{Therapeutic / Pharmacological effects of Chlorogenic acid}

Chlorogenic acid, like many other plant derived compounds, exerts a wide range of pharmacological activities which can be exploited as therapeutic equivalents to that of commercial

(C) 2019 Life Science Informatics Publication All rights reserved

Peer review under responsibility of Life Science Informatics Publications 
drugs.

The following are the therapeutic uses if chlorogenic acid:

a) Chlorogenic acid as an anti-diabetic and anti-obesity supplements

Metabolic disorders of glucose and lipids are intertwined with occurrence amelioration of obesity, diabetes, hepatic steatosis, cardiovascular disease, and cancer. Intracellular glucose and lipid metabolic homeostasis is thus indispensable for basic functioning of cells and thus of organism [12]. Chlorogenic acid or CGA has been postulated to modulate glucose and lipid metabolism in vivo in both healthy and genetically metabolic disordered conditions [13-15].

The following table summarizes the mode of action of CGA on glucose and lipidmetabolism:

Table 1a: Effect of Chlorogenic acid on glucose metabolism

\begin{tabular}{|c|c|}
\hline \multicolumn{2}{|r|}{ Effect On Glucose Metabolism } \\
\hline Effects & Mode of action \\
\hline $\begin{array}{l}\text { Hypoglycemic } \\
\text { and Antidiabetic } \\
\text { Effect }\end{array}$ & $\begin{array}{l}\text { In a research conducted by Bassoli et al it was found that CGA encouraged } \\
\text { the reduction in the plasma glucose peak by attenuating intestinal glucose } \\
\text { absorption demonstrating the effect of CGA as a glycaemic index lowering } \\
\text { agent thus reducing the liability of T2 diabetes mellitus [16].Anti diabetic } \\
\text { effect is endeavoured by stimulating uptake of glucose in both insulin- } \\
\text { sensitive and insulin-resistant adipocytes by enhancing the uptake of 2-[N- } \\
\text { (7-nitrobenz-2-oxa-1,3-diazol-4-yl)amino]-2-deoxy-d-glucose(2-NBDG)[17]. }\end{array}$ \\
\hline $\begin{array}{l}\text { Stimulation } \\
\text { of Insulin } \\
\text { Secretion }\end{array}$ & $\begin{array}{l}\text { In a study conducted by Touch et al., it was recounted that CGA increased } \\
\text { glucose uptake in L6 muscular cells and also stimulates insulin secretion } \\
\text { from the INS-1E insulin-secreting cell line and rat islets of } \\
\text { Langerhans[18]. }\end{array}$ \\
\hline $\begin{array}{l}\text { Improving Glucose } \\
\text { Tolerance and } \\
\text { Insulin Resistance }\end{array}$ & $\begin{array}{l}\text { CGA improves Glucose tolerance and Insulin resistance by the following } \\
\text { mechanism: } \\
\text { - Improvement of Cellular Mechanisms } \\
\text { - Inhibition of the Activity of } \alpha \text {-Glucosidase } \\
\text { - Alteration of GIP Concentrations } \\
\text { - Activation of AMPK } \\
\text { - Inhibition of HMG CoA Reductase } \\
\text { - Strengthening the Activity of Carnitine PalmitoylTransferase } \\
\text { - Inhibition of G-6-Pase Expression and } \\
\text { - Up regulation of Expression of Hepatic PPAR- } \alpha[19] .\end{array}$ \\
\hline
\end{tabular}


Table 1b: Effect of Chlorogenic acid on lipid metabolism

\begin{tabular}{|l|l|}
\hline \multicolumn{2}{|l|}{ Effect On Lipid Metabolism } \\
\hline Effects & Mode of action \\
\hline $\begin{array}{l}\text { Lowering Serum and } \\
\text { Hepatic CG and TG } \\
\text { Levels }\end{array}$ & $\begin{array}{l}\text { CGA are hypoglycemic agents and may affect lipid metabolism } \\
\text { by decreasing plasma cholesterol, triacylglycerol and liver } \\
\text { triacylglycerolsconcentrations significantly [13]. }\end{array}$ \\
\hline $\begin{array}{l}\text { Reducing LDL } \\
\text { Oxidation Susceptibility } \\
\text { and Decreasing LDL- }\end{array}$ & $\begin{array}{l}\text { CGA sway the effects of cardiovascular risk by reducing LDL } \\
\text { oxidation susceptibility and decreasing LDL-cholesterol and } \\
\text { malondialdehyde (MDA) levels [20-21]. }\end{array}$ \\
\hline $\begin{array}{l}\text { Levels } \\
\text { and Activating Fat } \\
\text { Metabolism in the Liver }\end{array}$ & $\begin{array}{l}\text { CGA inhibits fat absorption and activation of fat metabolism in } \\
\text { liver [22]. } \\
\text { Improvement of } \\
\text { Obesity- Related }\end{array}$ \\
$\begin{array}{l}\text { Hormones Levels } \\
\text { Chlorogenic acid significantly inhibited fatty acid synthase, 3- } \\
\text { hydroxy-3-methylglutaryl CoA reductase, and acyl-CoA } \\
\text { cholesterol acyltransferase activities, while they increased fatty } \\
\text { acid beta-oxidation activity and peroxisome proliferator- } \\
\text { activated receptors alpha expression in the liver compared to } \\
\text { the high-fat group [23]. }\end{array}$ \\
\hline
\end{tabular}

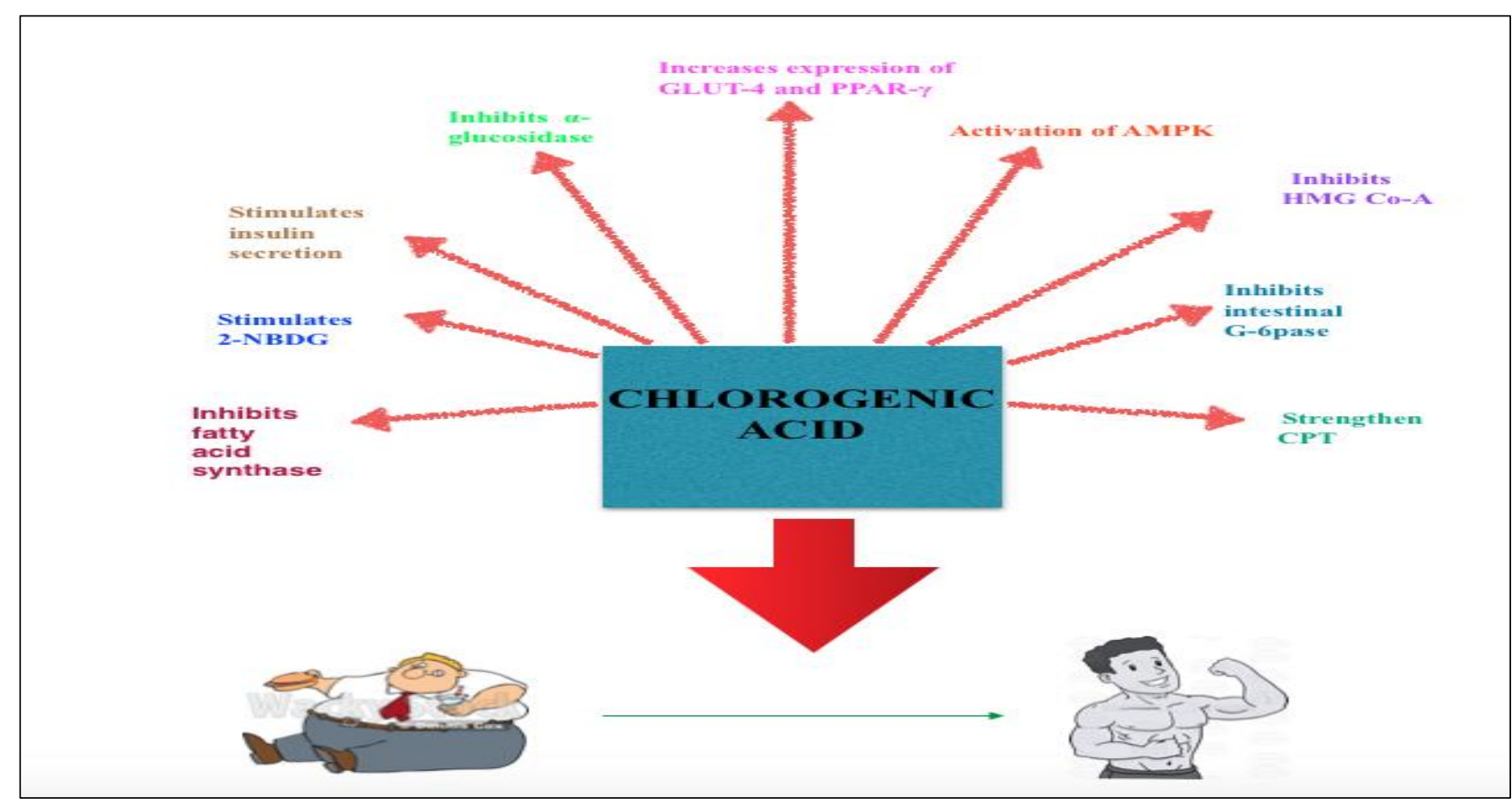

Figure 3: schematic diagram on effect of Chlorogenic acid on glucose and lipid metabolism Abbreviations: 2NBDG-2-[N-(,3-diazol-4-yl) amino]-2-deoxy-d-glucose; AMPKAMP activated 
protein kinase; HMG Co-A- $\beta$ - hydroxyl- $\beta$-methyl glutaric acyl coenzyme A reductase; G-6paseglucose-6-phosphatase; CPT- carnitine palmitoyl transferase.

\section{a) Chlorogenic acid as an anticancerous supplement}

In recent years, the cogency of chlorogenic acid in anti cancerous activity which is customarily accompanied with low toxicity has been widely studied. Yuan Yan et al.,, designed an experiment using human HCC cell lines, HepG2 and Hep3B, and observed the 5-FU-induced inhibition of HCC cell proliferation. The combined treatment of 5-FU with CGA enhanced this inhibition. 5-FU stimulated the overproduction of ROS, and the combination of 5-FU and CGAled toanevenmore prominent overproduction of ROS. Moreover, the combination of 5-FUandCGA led to inactivated ERK1/2. CGA could enhance the 5-FU-induced inhibition of HCC cell proliferation by the inactivation of ERK1/2 through the overproduction of ROS [24]. Apoptosis can be divided into caspase-dependent and -independent and mitochondria- dependent and -independent signal pathways [25, 26]. Chlorogenic acid induced apoptosis through the activation of caspase-3 [27]. It has also been reported that agents which induce apoptosis can be divided into mitochondriadependent and - independent pathways [26]. Chlorogenic acid induced apoptosis in U937 cells through a mitochondria-dependent pathway [27]. CGA potentially affect the cell survival by disrupting the mitochondrial structure and metabolism [28, 29]. LDH assays have been used to determine cell-mediated cytotoxicity and also to identify mediators that induce cytolysis [30]. LDH is a soluble cytoplasmic enzyme that is present in most of the cells and is released into blood stream or extracellular space when the plasma membrane is damaged. The leakage of LDH is another marker of cytotoxicity; treatment of HCT-116 cells with CGA7 resulted in insignificant concentration dependent increase in the LDH levels in cell culture supernatant. This indicates that the cytotoxicity of CGA7 against HCT-116 cells might be attributed to the cell membrane destructive effects of CGA7 [2]. CGA7 induced activation of PARP-1, and caspase 9 (the proteins which are activated during apoptosis) in a dose dependent manner [2]. PARP-1cleavage is reported as a marker for apoptosis and is one of the important targets for caspases [31,33]. In the study conducted by K. Goutham chandra et al., it was observed PARP-1 cleavage and Caspase 9 activation demonstration that CGA7 triggers activation of mitochondrial pathway of apoptosis [2]. 


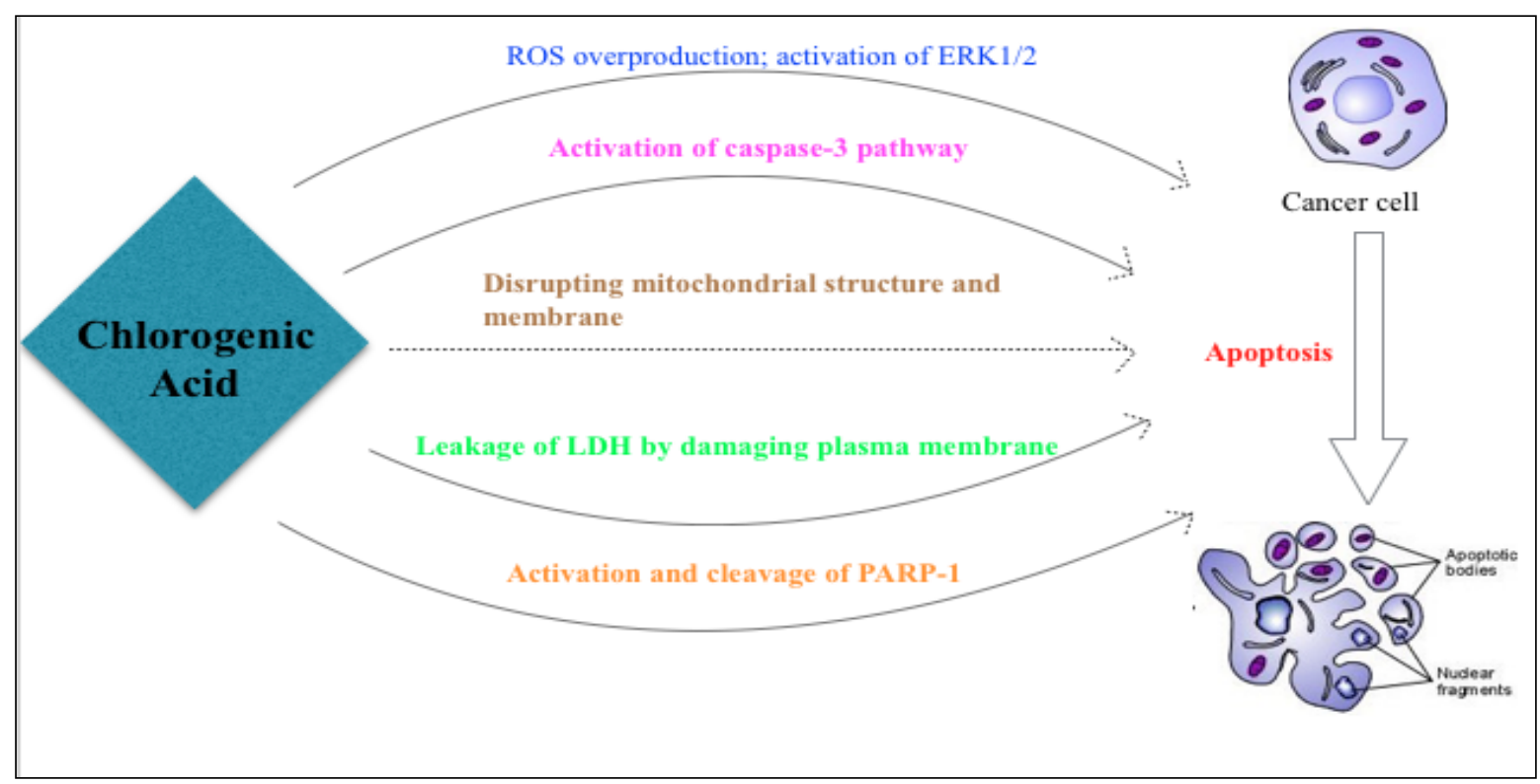

Figure 4: Chlorogenic acid induced apoptosis.

\section{b) Chlorogenic acid as an antibacterialsubstance}

Chlorogenic acid (CGA) which is a nonvolatile organic acid found in coffee, inhibit thegrowth of some Gram-positive microorganisms such as Staphylococcus aureus, Bacillus cereus, Lactobacillus bulgaricus, Streptococuslactis and Streptococcus faecalisand Gram-negative bacteria like Escherichia coli, Salmonella typhiand Pseudomonasauerginosa. The outer membrane of Gram negative bacteria consists of lipopolysaccharides and carbohydrates and requires divalent cations to maintain the integrity of the cell membrane. Chlorogenic acid because of its negative surface charge, binds to the $\mathrm{OM}$ by electrostatic interactions and chelate $\mathrm{Mg} 2+$, disrupting the $\mathrm{OM}$, leading to the loss of the barrier function. Chlorogenic acid probably acts on the plasma membrane by increased permeabilization. Chlorogenicacidfirstdisruptsthecellmembrane permeability andthen depolarizes thebacterialcell membrane. Nucleotide leakage experiments elucidated that chlorogenic acid increased the membrane permeabilization, and caused the leakage of nucleotide[31].

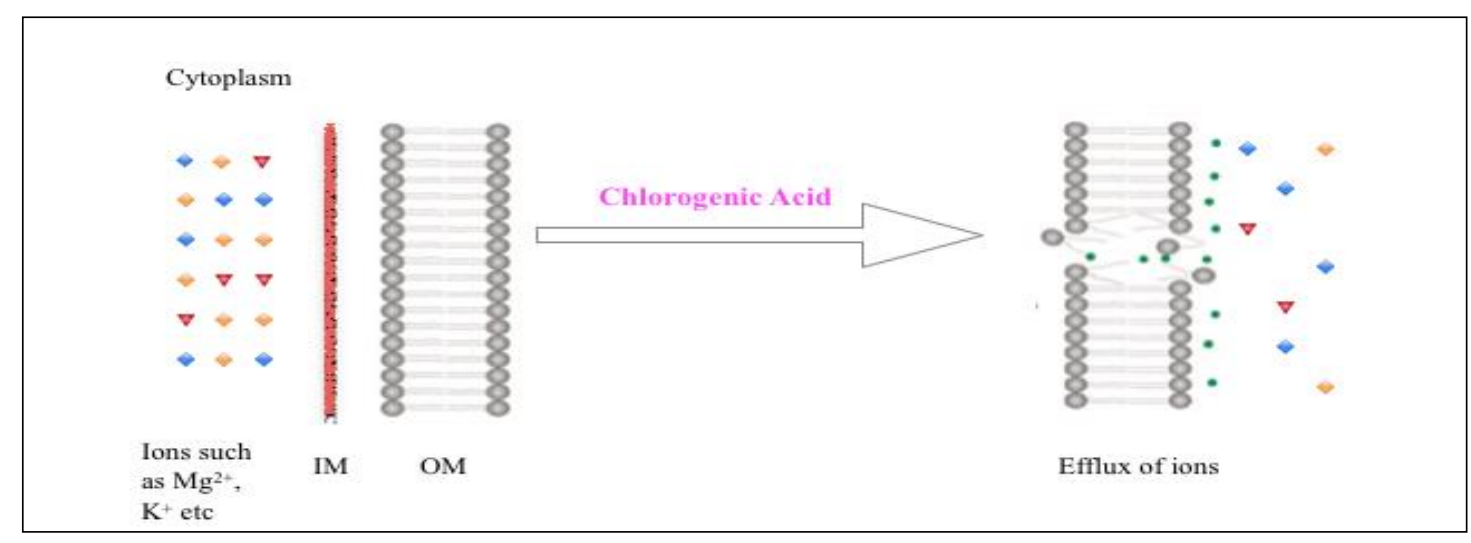

Figure 5: Chlorogenic acid induced membrane permeabilization.

Abbreviations: IM- Inner membrane, OM- outer membrane.

(C) 2019 Life Science Informatics Publication All rights reserved

Peer review under responsibility of Life Science Informatics Publications 


\section{c) Chlorogenic acid helps to regulate blood pressure in hypertensivepeople}

In a clinical trial conducted by Takuba et al., Chlorogenic acid in which a depressor effect of CGA was shown in patients with mild hypertension. The resulting hypotensive effect of CGA was due to NO mediated vasodilation [33] thus inducing muscle cell relaxation and blood vessel dilation. NO deficiency leads to hypertension and CGA intake improves NO bioavailability in hypertensive patients[34].

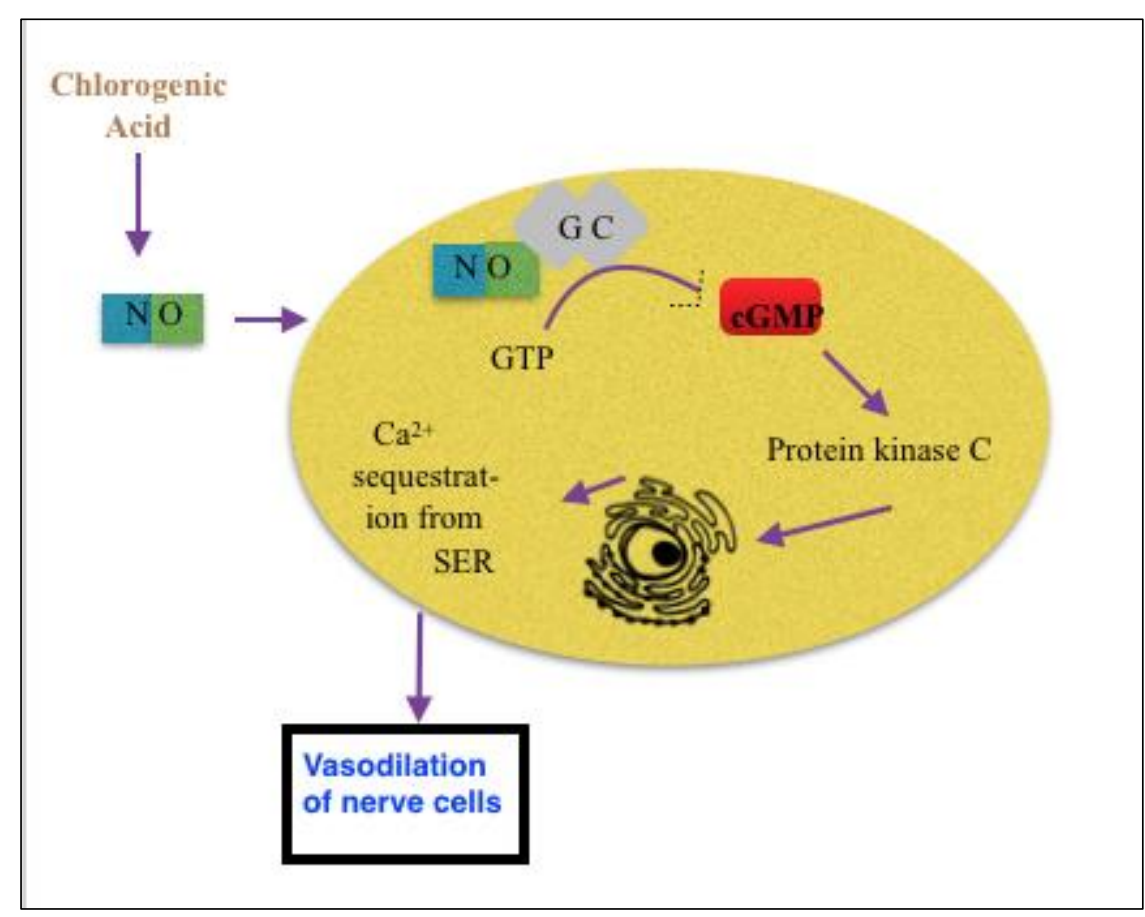

Figure 6: Vasodilation induced by CGA in smooth muscle cell

Abbreviations: NO- Nitric oxide, GC- Guanylyl cyclase, cGMP-cyclic Guanosine monophosphate, SER-Smooth endoplasmic reticulum.

\section{d) Chlorogenic acid as an anti-inflammatoryagent}

In a study conducted by S.J Hwang et al., CGA treatment was given to inflamed RAW 264.7cells. [RAW 264.7 cells were previously swollen from treatment with lipopolysaccharide. In contrast to normal cells, CGA treatment to LPS-induced inflammation cells reduces inflammation by decreasing NO production mediated by down-regulation of iNOS. In addition to reducing NO concentration it also suppresses pro-inflammatory cytokines such as IL-1b, TNF-a, and IL-6, as well as the chemokine CXCL1 through down-regulation of NF-KBand inhibition of Ninj1, which is important for leukocyte infiltration [35]. Thus, Chlorogenic acid is a conjectural anti-inflammatory drug for regulating the adhesion and trafficking of leukocytes in leukocyte-mediated inflammatory diseases.

\section{e) Chlorogenic acid has Neuroprotectiveeffects.}

Chlorogenic acid can convalesce brain function and neurodegenerative disorders. In a study conducted by S.H Kwon et al., scopolamine-induced amnesic mice were treated with chlorogenic acid. CGA administration significantly inhibited acetylcholinesterase in hippocampus and frontal 
cortex in a dose dependant manner. Moreover, the antioxidant property of CGA ameliorated the oxidative stress which significantly contributes to the perturbations and calcium homeostasis andsubsequent apoptosis as seen in Alzheirmer's patients [36]. In a study conducted by Shen et al.,, CGA significantly suppressed NO production and TNF- $\alpha$ release in LPS-stimulated primary microglia. In addition, CGA decreased LPS-stimulated phosphorylation and degradation of inhibitory kappa B-alpha $(\mathrm{I} \kappa \mathrm{B} \alpha)$, and prevented translocation of nuclear factor-kappaB $(\mathrm{NF}-\kappa \mathrm{B})$. Furthermore, CGA prevented neurotoxicity caused by microglial activation and ultimately improved survival of dopaminergic (DA) neuron [37]. Chlorogenic acid prevented the toxic effects of alpha-synuclein, the protein implicated in the destruction of dopamine-containing neurons and the development of Parkinson's disease [38].

Table 2: Summarization on the therapeutic effect of Chlorogenic acid

\begin{tabular}{|c|c|c|}
\hline Main role & Effects & Molecular mechanism \\
\hline Anti diabetic and & $\begin{array}{l}\text { Hypoglycemic and Antidiabetic } \\
\text { Effect }\end{array}$ & $\begin{array}{l}\unlhd[\mathrm{N}-(7-\text { nitrobenz-2-oxa-1,3- } \\
\text { diazol-4-yl)amino]-2-deoxy- } \\
\text { d-glucose(2-NBDG) }\end{array}$ \\
\hline \multirow{6}{*}{ Anti obesity } & Stimulation of Insulin Secretion & $\uparrow$ Insulin \\
\hline & $\begin{array}{l}\text { Improving Glucose Tolerance and } \\
\text { Insulin Resistance }\end{array}$ & $\begin{array}{l}\checkmark \text { AMPK; } \\
\text { XHMG Co-A; } \\
\text { XG-6-Pase; } \\
\sqrt{ } \text { PPAR- } \alpha\end{array}$ \\
\hline & $\begin{array}{l}\text { Lowering Serum and Hepatic CG } \\
\text { and TG Levels }\end{array}$ & $\begin{array}{l}\downarrow \text { cholesterol, triacylglycerol } \\
\text { and liver triacylglycerols }\end{array}$ \\
\hline & $\begin{array}{l}\text { Reducing LDL Oxidation } \\
\text { Susceptibility and Decreasing } \\
\text { LDL-Cholesterol and MDA Levels }\end{array}$ & $\begin{array}{l}\downarrow \text { LDL-cholesterol and } \\
\text { malondialdehyde (MDA) }\end{array}$ \\
\hline & $\begin{array}{l}\text { Inhibiting Fat Absorption and } \\
\text { Activating Fat Metabolism in the } \\
\text { Liver }\end{array}$ & $\begin{array}{l}\downarrow \text { fat absorption; } \\
\uparrow \text { fat metabolism }\end{array}$ \\
\hline & $\begin{array}{l}\text { Improvement of Obesity-Related } \\
\text { Hormones Levels }\end{array}$ & $\begin{array}{l}\downarrow \text { fatty acid synthase, } 3 \text { - } \\
\text { hydroxy-3-methylglutaryl } \\
\text { CoA reductase, and acyl-CoA } \\
\text { cholesterol acyltransferase }\end{array}$ \\
\hline$\underline{\text { Anti cancerous }}$ & Apoptosis by ROS overproduction & $\begin{array}{l}\uparrow \operatorname{ROS} ; \\
\text { } \text { ERK } 1 / 2\end{array}$ \\
\hline
\end{tabular}




\begin{tabular}{|c|c|c|}
\hline \multirow[t]{4}{*}{ Roy RJLBPCS 2019} & www.rjlbpes.com & fe Science Informatics Publication \\
\hline & Apoptosis by caspase pathway & $\begin{array}{l}\uparrow \text { Caspase } 3 ; \\
\downarrow \text { Caspase } 9 \text {. }\end{array}$ \\
\hline & $\begin{array}{l}\text { Apoptosis by mitochondria } \\
\text { dependent pathway }\end{array}$ & $\begin{array}{l}凶 \text { mitochondrial membrane } \\
\& \text { metabolism }\end{array}$ \\
\hline & $\begin{array}{l}\text { Apoptosis by damaging plasma } \\
\text { membrane }\end{array}$ & $\begin{array}{l}\otimes \uparrow \mathrm{LDH} \& \text { \& plasma } \\
\text { membrane }\end{array}$ \\
\hline$\underline{\text { Antibacterial }}$ & Permeablization of membrane & $\begin{array}{l}\text { 区Outer membrane } \otimes \\
\mathrm{Mg} 2+\end{array}$ \\
\hline $\begin{array}{l}\text { Lowering blood } \\
\text { pressure }\end{array}$ & Vasodilation & $\uparrow$ NO production \\
\hline Anti-inflammatory & $\begin{array}{l}\text { Suppression of pro-inflammatory } \\
\text { substances }\end{array}$ & $\begin{array}{l}\downarrow N O \text { production; } \\
\text { downregulation iNOS; } \downarrow \text { IL-1b } \\
\text { TNF-a, and IL-6 \& } \\
\text { chemokine CXCL1; } \\
\text { down regulation NF- KB; } \\
\text { XNinj1 }\end{array}$ \\
\hline
\end{tabular}

Symbolic representation: $(\uparrow)$ increase; $(\downarrow)$ decrease; $(\hookleftarrow)$ uptake; $(\otimes)$ leakage/chelate; $(\bigotimes)$ disruption; $(\mathbf{X})$ inhibition; $(\boldsymbol{})$ activation.

\section{CONCLUSION}

Our present study strongly suggests a generalized relation of the naturallyoccuring compound in green coffee beans, chlorogenic acid and its beneficial biological activity. The presence of chlorogenic acid, a phenolic compound, in green coffee possessesanti-oxidant, antibacterial and lipolytic activity. Chlorogenic acid has many freehydroxyl groups which is responsible for its remarkable antioxidation properties.Chlorogenic acid is capable of scavenging ROS and thus reducing oxidative stresses thuscan render a wide variety of pharmacological activity such as cardioprotective,renoprotective, hepatoprotective etc. Green coffee bean extract also inhibits the growthof pathogenic microorganism as was observed during antibacterial study. Like antibioticschlorogenic acid inhibits the growth of microorganism by altering membranepermeability. In Well diffusion antibacterial assay clear zone of inhibition can beobserved. Chlorogenic acid is both effective against Gram positive and Gram negativepathogenic bacterial strains. The lipolytic assay of purified sample exhort the fact thatchlorogenic acid also possess lipolytic activity and thus theorising the fact thatconsumption of green coffee will allow an individual to lose weight faster than usual and also renders the patient free from diabetes. Chlorogenic acid have huge impact on fatmetabolism. It inhibits the expression of certain enzymes of different lipid biosyntheticpathways such as HMG Co-A reductase, fatty acid 
synthase and acyl Co-Aacyltransferase as well as induces lipid catabolism in liver. Thus chlorogenic acid couldact as a dietary supplement which can implement a wide variety of health benefits toindividuals such as antidiabetic, antiobese, anticancerous, antibacterial, reduceshypertension, antiinflammatory and also has neuroprotective effects.

\section{ACKNOWLEDGEMENT}

Foremost, I would like to express my cordial thanks to Almighty andmy mentor cum advisor Prof.Monojit Banerjee, Triveni Devi Bhalotia College, Raniganj for his passionate participation and input in writing this research article. I am indebted to Prof. S.S Kanwar, Department of Biotechnology, Himachal Pradesh University for introducing me to this topic. Words will fall short for the continuous abutment and faith of my parents in my ingenuity in writing this article.

\section{CONFLICT OF INTEREST}

Author doesn't have any conflict of interest regarding this present study.

\section{REFERENCES}

1. Maalik A, Bukhari SM, zaidi A, Shah K, Khan FA. Chlorogenic acid: A pharmacologically potent molecule. Acta Pol Pharm. 2016; 73:851-854.

2. Gouthamchandra K, Sudeep H, Venkatesh B, Prasad KS. Chlorogenic acid complex (CGA7), standardized extract from green coffee beans exerts anticancer effects against cultured human colon cancer HCT-116 cells. Food Sci and Human Well. 2017; 6:147-153.

3. Clifford MN, Johnston KL, Knight S, Kuhnert N. Hierarchical Scheme for LC-MSnIdentification of Chlorogenic Acids. Journal of Agri and Food Chem. 2003; 51:2900-2911.

4. Han T, Zhang QY, Zhang H, Wen J, Wang Y, Huang B-K, et al., Authentication and quantitative analysis on the chemical profile of Xanthium fruit (Cang-Er-Zi) by high-performance liquid chromatography-diode-array detection tandem mass spectrometry method. AnalytChemiActa. 2009; 634:272-278.

5. Clifford M, Jarvis T. The chlorogenic acids content of green robusta coffee beans as a possible index of geographic origin. Food Chem. 1988; 29:291-298.

6. Herrmann K. Caffeic and chlorogenic acids Pharmazie. 1956; 11:433-449.

7. Schneider L. Betulae folium, Orthosiphonis folium, and Solidaginisherba are herbal remedies used in Germany for their diuretic effects. European med agen. 2010; 1:2-3.

8. Clifford MN. Chlorogenic acids and other cinnamates - nature, occurrence, dietary burden, absorption and metabolism. Journal of the Sci of Food and Agri. 2000; 80:1033-1043.

9. Vogt T. Phenylpropanoid Biosynthesis. Molecular Plant. 2010; 3:2-20.

10. Koshiro Y, Jackson MC, Katahira R, Wang M-L, Nagai C, Ashihara H. Biosynthesis of Chlorogenic Acids in Growing and Ripening Fruits of Coffeaarabica and Coffeacanephora Plants. Zeitschrift für Naturforschung C. 2007; 62:731-42. 
11. Lallemand LA, Zubieta C, Lee SG, Wang Y, Acajjaoui S, Timmins J, et al., A Structural Basis for the Biosynthesis of the Major Chlorogenic Acids Found in Coffee. Plant Physi. 2012; 160:249260.

12. Kopelman PG. Obesity as a medical problem. Nature. 2000; 404:635-643.

13. Sotillo DVRD, Hadley M. Chlorogenic acid modifies plasma and liver concentrations of: cholesterol, triacylglycerol, and minerals in (fa/fa) Zucker rats. Journal of NutriBiochem. 2002; $13: 717-726$.

14. Sotillo DVRD, Hadley M, Sotillo JE. Insulin receptor exon 11 /- is expressed in Zucker (fa/fa) rats, and chlorogenic acid modifies their plasma insulin and liver protein and DNA. The Journal of Nutri Biochem. 2006; 17:63-71.

15. Nicasio P, Aguilar-Santamaría L, Aranda E, Ortiz S, González M. Hypoglycemic effect and chlorogenic acid content in twoCecropia species. Phytotherapy Research. 2005;19:661-664.

16. Bassoli BK, Cassolla P, Borba-Murad GR, Constantin J, Salgueiro-Pagadigorria CL, Bazotte RB, et al., Chlorogenic acid reduces the plasma glucose peak in the oral glucose tolerance test: effects on hepatic glucose release and glycaemia. Cell Biochem and Func. 2008; 26:320-328.

17. Alonso-Castro AJ, Miranda-Torres AC, González-Chávez MM, Salazar-Olivo LA. CecropiaobtusifoliaBertol and its active compound, chlorogenic acid, stimulate 2-NBDglucose uptake in both insulin-sensitive and insulin-resistant 3T3 adipocytes. Journal of Ethnopharmacology. 2008; 120:458-464.

18. Tousch D, Lajoix AD, Hosy E, Azay-Milhau J, Ferrare K, Jahannault C, et al., Chicoric acid, a new compound able to enhance insulin release and glucose uptake. Biochem and Biophy Res Com. 2008; 377:131-135.

19. Meng S, Cao J, Feng Q, Peng J, Hu Y. Roles of Chlorogenic Acid on Regulating Glucose and Lipids Metabolism: A Review. Evidence-Based Complem and Alt Med. 2013; 2013:1-11.

20. Yukawa GS, Mune M, Otani H, Tone Y, Liang X-M, Iwahashi H, et al., Effects of Coffee Consumption on Oxidative Susceptibility of Low-Density Lipoproteins and Serum Lipid Levels in Humans. Biochem. 2004; 69:70-74.

21. Laranjinha JA, Almeida LM, Madeira VM. Reactivity of dietary phenolic acids with peroxyl radicals: Antioxidant activity upon low density lipoprotein peroxidation. BiochemPharmaco. 1994;48:487-494.

22. Shimoda H, Seki E, Aitani M. Inhibitory effect of green coffee bean extract on fat accumulation and body weight gain in mice. BMC Complem and Alt Med. 2006; 6:9

23. Cho A-S, Jeon S-M, Kim M-J, Yeo J, Seo K-I, Choi M-S, et al., Chlorogenic acid exhibits antiobesity property and improves lipid metabolism in high-fat diet-induced-obese mice. Food and ChemToxico. 2010; 48:937-943. 
24. Yan Y, Li J, Han J, Hou N, Song Y, Dong L. Chlorogenic acid enhances the effects of 5fluorouracil in human hepatocellular carcinoma cells through the inhibition of extracellular signalregulated kinases. Anti-Cancer Drugs. 2015; 26:540-546.

25. Kluck RM. The Release of Cytochrome c from Mitochondria: A Primary Site for Bcl-2 Regulation of Apoptosis. Science. 1997; 275:1132-1136.

26. Lavrik IN. Caspases: pharmacological manipulation of cell death. Journal of Clin Invest. 2005; 115:2665-2672.

27. Yang JS, Liu CW, Ma yi-S, Weng SW, Tang NY, Wu SH, et al., Chlorogenic Acid Induces Apoptotic Cell Death in U937 Leukemia Cells through Caspase- and Mitochondria-dependent Pathways. In vivo. 2012; 26:971-978.

28. Burgos-Morón E, Calderón-Montaño JM, Orta ML, Pastor N, Pérez-Guerrero C, Austin C, et al., The Coffee Constituent Chlorogenic Acid Induces Cellular DNA Damage and Formation of Topoisomerase I- and II-DNA Complexes in Cells. Journal of Agri and Food Chem. 2012;60:7384-7391.

29. Asharani PV, Mun GLK, Hande MP, Valiyaveettil S. Cytotoxicity and Genotoxicity of Silver Nanoparticles in Human Cells. ACS Nano. 2008; 3:279-290.

30. Foldbjerg R, Dang DA, Autrup H. Cytotoxicity and genotoxicity of silver nanoparticles in the human lung cancer cell line, A549. Archives of Toxico. 2010; 85:743-750.

31. Lou Z, Wang H, Zhu S, Ma C, Wang Z. Antibacterial Activity and Mechanism of Action of Chlorogenic Acid. Journal of Food Science. 2011;76:M398-403.

32. Tuan P, Kwon D, Lee S, Arasu M, Al-Dhabi N, Park N, et al., Enhancement of Chlorogenic Acid Production in Hairy Roots of Platycodon grandiflorum by Over-Expression of An Arabidopsis thaliana Transcription Factor AtPAP1. Int Journal of Mol Sci. 2014; 15:14743-14752.

33. Suzuki A, Kagawa D, Ochiai R, Tokimitsu I, Saito I. Green Coffee Bean Extract and Its Metabolites Have a Hypotensive Effect in Spontaneously Hypertensive Rats. Hypertension Res. 2002; 25:99-107.

34. Watanabe T, Arai Y, Mitsui Y, Kusaura T, Okawa W, Kajihara Y, et al., The Blood PressureLowering Effect and Safety of Chlorogenic Acid from Green Coffee Bean Extract in Essential Hypertension. Clin and Exp Hypertension. 2006; 28:439-449.

35. Hwang SJ, Kim Y-W, Park Y, Lee H-J, Kim K-W. Anti-inflammatory effects of chlorogenic acid in lipopolysaccharide-stimulated RAW 264.7 cells. Inflam Res. 2013;63:81-90.

36. Kwon SH, Lee HK, Kim JA, Hong SI, Kim HC, Jo TH, et al., Neuroprotective effects of chlorogenic acid on scopolamine-induced amnesia via anti-acetylcholinesterase and anti-oxidative activities in mice. Europ Journal of Pharmaco. 2010; 649:210-7. 
37. Shen W, Qi R, Zhang J, Wang Z, Wang H, Hu C, et al., Chlorogenic acid inhibits LPS-induced microglial activation and improves survival of dopaminergic neurons. Brain Res Bulletin. 2012;88:487-494.

38. Teraoka M, Nakaso K, Kusumoto C, Katano S, Tajima N, Yamashita A, et al., Cytoprotective effect of chlorogenic acid against $\alpha$-synuclein-related toxicity in catecholaminergic PC12 cells. Journal of ClinBiochem and Nutri. 2012; 51:122-127. 